\title{
Silk Powder from Cocoons and Woven Fabric as a Potential Bio-Modifier
}

\author{
Anna Baranowska-Korczyc ${ }^{1, *(\mathbb{D})}$, Andrzej Hudecki ${ }^{2}$, Irena Kamińska ${ }^{1}$ (D) and Małgorzata Cieślak ${ }^{1}$ (D) \\ 1 Department of Chemical Textiles Technologies, Łukasiewicz Research Network-Textile Research Institute, \\ 5/15 Brzezinska Street, 92-103 Lodz, Poland; irena.kaminska@iw.lukasiewicz.gov.pl (I.K.); \\ malgorzata.cieslak@iw.lukasiewicz.gov.pl (M.C.) \\ 2 Department of Functional Materials, Łukasiewicz Research Network-Institute of Non-Ferrous Metals, \\ 5 Sowińskiego Street, 44-100 Gliwice, Poland; andrzej.hudecki@imn.gliwice.pl \\ * Correspondence: anna.baranowska-korczyc@iw.lukasiewicz.gov.pl
}

Citation: Baranowska-Korczyc, A. Hudecki, A.; Kamińska, I.; Cieślak, M Silk Powder from Cocoons and Woven Fabric as a Potential Bio-Modifier. Materials 2021, 14, 6919. https://doi.org/10.3390/ma14226919

Academic Editor:

Malgorzata Zimniewska

Received: 28 September 2021

Accepted: 9 November 2021

Published: 16 November 2021

Publisher's Note: MDPI stays neutral with regard to jurisdictional claims in published maps and institutional affiliations.

Copyright: (c) 2021 by the authors. Licensee MDPI, Basel, Switzerland. This article is an open access article distributed under the terms and conditions of the Creative Commons Attribution (CC BY) license (https:/ / creativecommons.org/licenses/by/ $4.0 /)$.
Abstract: Silk, as a protein fiber characterized by high biocompatibility, biodegradability, and low toxicity, is mainly used as textile structures for various purposes, including for biological applications. The key issue for unlimited silk applicability as a modifier is to prepare its relevant form to cover or introduce to other materials. This study presents silk powder fabrication from Bombyx mori cocoons and non-dyed silk woven fabric through cryogenic milling. The cocoons were milled before and after the degumming process to obtain powders from raw structures and pure fibroin. The powder morphology and composition were analyzed using scanning electron microscopy and energy dispersive spectroscopy. The influence of the milling on the silk structure was studied using infrared and Raman spectroscopies, indicating that silk powders retained dominant $\beta$-sheet structure. The powders were also analyzed by differential scanning calorimetry and thermogravimetric techniques. The thermal endothermic peak and onset temperature characteristic for silk decomposition shifted to the lower values for all powders, indicating less thermal stability. However, the process was found to be an efficient way to obtain silk powders. The new milled form of silk can allow its introduction into different matrices or form coatings without using any harsh solvents, enriching them with new features and make more biologically friendly.

Keywords: silk; cryogenic milling; fibroin; bio-modifier; textiles; degumming

\section{Introduction}

Silk has been extensively studied as one of the most promising natural-origin materials for biotechnological and biomedical purposes [1]. Due to its unique properties, such as remarkable strength and toughness, high thermal stability, biocompatibility, biodegradability, low toxicity, and textile technological importance, it has been applied as a drug delivery system, scaffolds for tissue engineering, or for designing biosensors and wearable electronics [2]. Silk is a biopolymer composed of two unique proteins, fibroin and sericin. Silk in Bombyx mori (B. mori) cocoons is mostly formed by fibroin, about 70 to 80 wt.\%, which after degumming is commonly used in the textile industry and in medicine [3]. Fibroin exhibits high mechanical resistance due to antiparallel alignment of $\beta$-sheets in its protein secondary structure, hydrophilic and hydrophobic blocks in a semicrystalline polymer matrix, self-cooling ability, and a lack of inflammatory responses in humans [4]. Sericin is also applied for biomedical systems due to its high moisture, oxidation, and protection against UV radiation [5]. The excellent properties of both silk proteins mean that they are processed in many ways and forms including in vivo modification, regeneration, or post-treatments. Silk fibers can be dissolved, doped with different nanostructures, or form a base for various dimensionality systems, such as films, microspheres, or electrospun fibers [1]. Fibroin and sericin have been used mainly to improve the physical properties of various materials as well as to enhance their biocompatibility. 
However, most silk modification methods such as spin or dip coating and electrospinning, need to use harsh solvents (trifluoroacetic acid, lithium bromide, methanol, or formic acid) which limited the applicability of silk proteins $[2,6]$. The key issue for the unlimited use of silk as a bio-modifier is to prepare its relevant form to cover or introduce to other materials using physical techniques instead of wet chemistry methods. There are some reports which introduce milling techniques as a facile way for processing natural silk fibroin. The commercial mulberry, muga, and eri silk were degummed and pulverized to ultrafine powder using rotary and ball milling [7]. The fibroin from eri silk cocoon after removing sericin was also converted to powder through attritor and jet milling [8]. Raw B. mori silk was also degummed and treated by mechanical milling to obtain fibroin powder for efficient removal of toxic dyes from an aqueous solution [9]. The above reports were focused on fibroin pulverization, whereas the milling of raw cocoons can result in combining the advantageous properties of both proteins in the fibroin/sericin powder.

This study presents pulverization of different silk-based materials and includes not only fibroin but also raw B. mori cocoons and woven fabric. The raw cocoons were grinding to obtain powder composed of fibroin and sericin for the combining of the advantageous properties of both proteins. The possibility of silk powder formation from previously woven fabric was evaluated. The process of cryogenic milling was selected as a method that does not generate heat since high temperatures can harmfully influence the protein structure and properties. The morphology and chemical composition of the powders obtained from three different sources were studied using, respectively, scanning electron microscopy (SEM) and energy dispersive spectroscopy (EDS). To evaluate the efficiency of the degumming process and silk structure, Raman and infrared spectroscopies were implemented in the study. It was found that sericin was effectively removed from the raw cocoon in the case of fibroin samples and all powders retain a dominant $\beta$-sheet structure. The thermal properties of all samples were analyzed using differential scanning calorimetry (DSC) and thermogravimetry/derivative thermogravimetry (TG/DTG). The thermal degradation process started at lower temperatures for all powders in comparison to the source materials. The thermal endothermic peak characteristic for silk decomposition also shifted to the lower values for all powders. Despite the slightly lower thermal stability caused by the fragmentation of the material, it has been shown that low-temperature silk grinding is an effective method of obtaining silk powders composed of sericin and fibroin mixture (or only fibroin). The protein powders can be introduced to the various systems without applying harsh solvents for various biological applications.

\section{Materials and Methods}

\subsection{Silk Cocoon Degumming and Cryogenic Milling}

Bombyx mori silk cocoons were obtained from a Chinese (Shenzhen) market supplier. Non-dyed silk woven fabric (mass per unit area of $70 \mathrm{~g} / \mathrm{m}^{2}$, thickness of $0.2 \mathrm{~mm}$, linear mass of yarns of $37 \mathrm{dtex}$ ) was obtained from Łukasiewicz Research Network-Textile Research Institute resources. The raw cocoons were cut to small pieces and degummed in an aqueous solution of $0.02 \mathrm{M}$ sodium carbonate $\left(\mathrm{Na}_{2} \mathrm{CO}_{3}\right.$, Sigma Aldrich, Poznań, Poland). $0.4 \mathrm{~g}$ of the cocoons were immersed in $200 \mathrm{~mL}$ of $\mathrm{Na}_{2} \mathrm{CO}_{3}$ for $40 \mathrm{~min}$ at $100{ }^{\circ} \mathrm{C}$. Then, silk fibroin was rinsed three times in cold distilled water and dried for $24 \mathrm{~h}$ at $40{ }^{\circ} \mathrm{C}$. To determine the fibroin content, the raw cocoons and cocoons after the degumming process were dried $\left(24 \mathrm{~h}\right.$ at $\left.40^{\circ} \mathrm{C}\right)$ and immediately weighted.

The milling process was carried out using cryogenic grinder (SPEX ${ }^{\circledR}$ SamplePrep, Metuchen, NJ, USA) of 6875D model (Figure 1). Before the milling process, the raw cocoons, cocoons after the degumming process (silk fibroin), and silk woven fabric were dried in the Christ Alpha 2-4LD dryer (Martin Christ Gefriertrocknungsanlagen $\mathrm{GmbH}$, Osterode am Harz, Germany) for $24 \mathrm{~h}$ at $30^{\circ} \mathrm{C}$. The samples of weight about $4 \mathrm{~g}$ were placed in polycarbonate vials of $100 \mathrm{~mL}$ volume with magnetically shuttling impactors. The samples before milling were immersed in liquid nitrogen in cryogenic milling vials for $60 \mathrm{~min}$ to freeze them. The milling process was repeated five times for $5 \mathrm{~min}$ with 2-min breaks 
without stirring to decrease the temperature in the chamber to the starting value and keep the sample frozen. The vial with the sample was continuously immersed in liquid nitrogen to maintain cryogenic temperatures. The single milling cycle was composed of 15 impactor blows. After the milling process, the samples were dried again to remove the excess water.

(a)

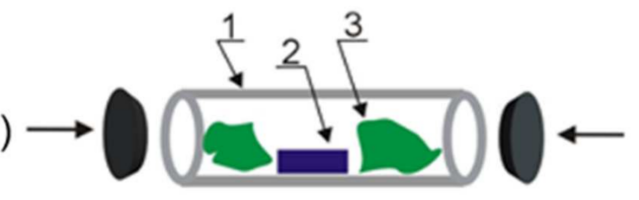

(b)

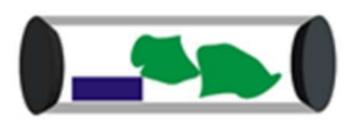

(c)

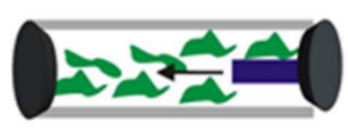

(d)

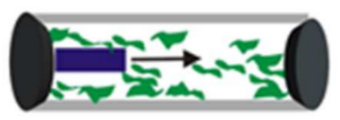

4

(e)

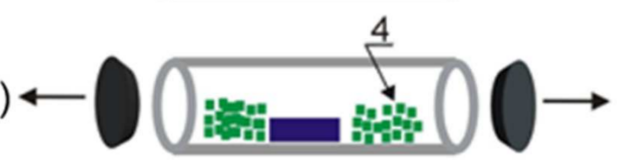

Figure 1. Scheme of the subsequent stages of milling process: (a) loading the sample into the vial, (b) closing the vial, (c) starting the grinding process, (c,d) sample grinding by magnetically shuttling impactor oscillating back and forth along the vial, and (e) removing powder from the vial. The numbers in the diagram label sequentially (1) the vial, (2) impactor, (3) sample, and (4) powder.

\subsection{Characterization of Silk-Based Powders}

The morphology of the samples was analyzed by using SEM VEGA 3 TESCAN (Tescan Osay Holding, Brno, Czech Republic) at an accelerating voltage of $20 \mathrm{kV}$. The samples for SEM analysis were covered with a thin gold layer of about $3 \mathrm{~nm}$. Chemical composition was investigated by EDS analysis (INCA Energy X-ray energy dispersion spectrometer, Oxford Instruments, Abingdon, UK) of three different area of $0.2 \mathrm{~mm}^{2}$, with an accelerating voltage of $20 \mathrm{kV}$ and pressure of $20 \mathrm{~Pa}$. The statistical analysis for EDS measurements were performed using the INCA energy software 450 (version 4.15). Raman spectra of the samples were obtained by using an inVia Renishaw Raman Microscopy System (Renishaw, Wotton-under-Edge, UK) with a 50× microscope objective (LEICA, Wetzlar, Germany). The excitation source was a laser with a wavelength of $785 \mathrm{~nm}$. Each Raman spectrum was obtained with four accumulations in the range of 600 to $2000 \mathrm{~cm}^{-1}$ corrected by the WiRETM5.3 software. The Raman spectra were presented without normalization. The analysis of the band intensity was based on the comparison of selected bands within one spectrum and then this intensity ratio was compared for all samples. The Fourier transformed infrared (FTIR) absorption spectra of silk sample were recorded using BRUKER Vertex 70 FTIR spectrometer with diamond ATR Golden Gate adapter(Bruker, Bremen, Germany) spectrometer, in a spectral range of $600 \mathrm{~cm}^{-1}$ to $4000 \mathrm{~cm}^{-1}$ with a resolution of $4 \mathrm{~cm}^{-1}$. The Raman and infrared spectra were collected at least three replicates for each sample.

The thermal properties were studied using DSC 204 F1 Phoenix calorimeter, (Netzsch, Selb, Germany) and TG 209F1 Libra (Netzsch, Selb, Germany) techniques. The thermal measurements were performed at least three replicates for each sample. The samples with a weight of about $4 \mathrm{mg}$ were placed in a ceramic crucible with a volume of $85 \mu \mathrm{L}$ and 
heated with a rate of $10^{\circ} \mathrm{C} \mathrm{min}^{-1}$ under nitrogen flow of $25 \mathrm{~mL} \mathrm{~min}{ }^{-1}$ in the temperature range of $20-600{ }^{\circ} \mathrm{C}$ and $20-800{ }^{\circ} \mathrm{C}$ for DSC and TG/DTG analysis, respectively. Student's $t$-test was used for comparison thermal properties between the samples before and after milling process.

\section{Results and Discussion}

\subsection{Powder Formation and SEM/EDS Studies}

In this study, silk powder was obtained by cryogenic milling (Figure 1) from raw silk cocoons, cocoons after the degumming (that is, fibroin), and woven silk textile (Figure 2a-c). The milling process allowed the silk processability without using harsh substances, such as trifluoroacetic acid, lithium bromide, or formic acid applied for fibroin coating formation or electrospinning $[2,6]$. The silk fibroin is characterized by high thermal stability with no clear thermal degradation below $200^{\circ} \mathrm{C}$ [10]. However, the milling procedures often referred to as processes carried out "at room temperature" can cause a significant increase in temperature, for example even to $600{ }^{\circ} \mathrm{C}$ for planetary ball milling [11]. The recent study indicated also that native silk is stable only between -10 and $55^{\circ} \mathrm{C}$ [12] due to sericin and fibroin additional temperature transition appearing, respectively, at about 45 and $65{ }^{\circ} \mathrm{C}$ prior to the main silk endothermic transition. The thermal denaturation was redefined for silk proteins as a loss of natural hydration shell, which results in structural reconfiguration in native material [12]. The low temperature was applied for the milling process, since silk cocoons are composed of natural fibers which need special treatment to avoid protein denaturation and changes in their structure and properties.
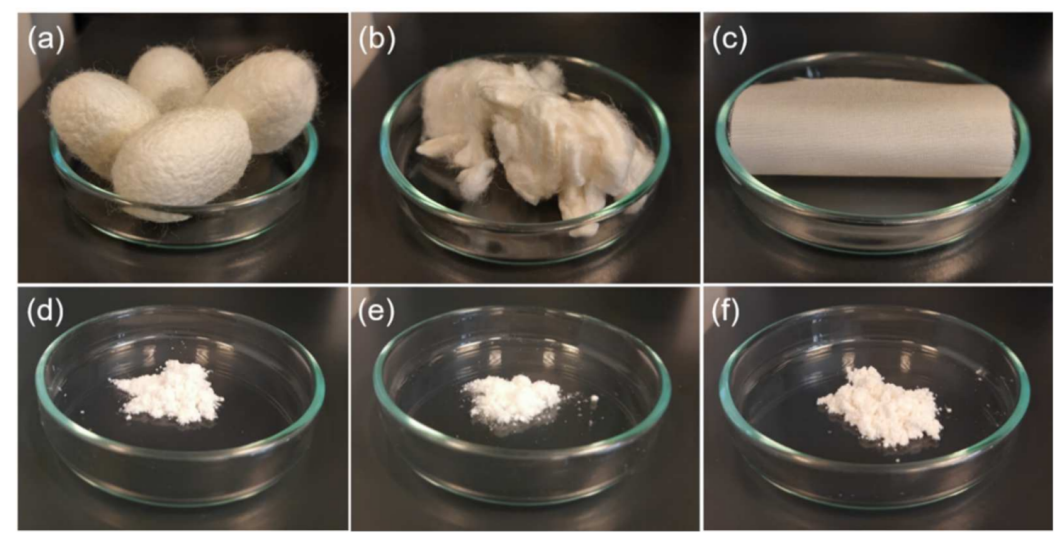

Figure 2. (a) Raw and (b) degummed silk cocoons, (c) silk fabric, and silk powders from (d) raw cocoons, (e) degummed cocoons, and (f) silk fabric.

The milling process is a facile way allowed to form effectively a silk powder from raw and degummed cocoons and fabric (Figure $2 \mathrm{~d}-\mathrm{f}$ ). The three materials were selected to evaluate the milling process of various silk-based materials and for further extension of the silk's applicability. Previously, only the fibroin was ground and applied for different systems $[7,8,10]$. The raw cocoons were chosen for the study to obtain a powdered modifier composed of fibroin and sericin. Sericin from cocoons of B. mori has attracted growing attention since its unique properties were characterized in many reports. This included promotion of collagen production, anti-inflammatory activity, controlled drug-release, and antioxidant properties [13]. The accumulation of specific properties of fibroin and sericin can expand significantly the application range of silk powder as a bio-modifier. The silk textile structure was selected to study the possibility of using woven fabric to form a powder and its properties as a potential modifier. This approach is consistent with recycling strategy of textile waste. The milling process can allow one to obtain regenerated silk in a form of powder from waste of silk woven textile structures during their production and from reused materials as well as waste generated during the process of obtaining silk from cocoons. 
The original materials significantly changed form due to the fragmentation of the samples. The morphology of the materials was also extensively modified. SEM images of the raw cocoons reveal typical structures of two fibroin filaments bonded together since they are originally extruded from two silkworm glands (Figure 3a). They remain together due to protein gum of sericin, visible on the fiber surface. The debris visible in the sample indicates the raw nature of the cocoons without applying any cleaning treatment. After the degumming process and removing sericin, the fibroin filaments are not bounded and their surface is smooth without additional components (Figure 3b). The silk fabric with plain weave contains the same yarn in warp and weft (Figure S1). The cryogenic milling caused fragmentation of the fibers of all original materials to a similar degree, the obtained fibroin filament segments are characterized by the size range of about 30 to $500 \mu \mathrm{m}$ (Figure $3 \mathrm{~d}-\mathrm{f}$ ). However, the process was slightly more efficient for the fabric sample, which shows the smallest fiber fragments of about 30-350 $\mu \mathrm{m}$ (Figure 3f). It indicates lower durability of this silk probably due to previous fabric manufacturing processes in comparison to raw and degummed cocoons.

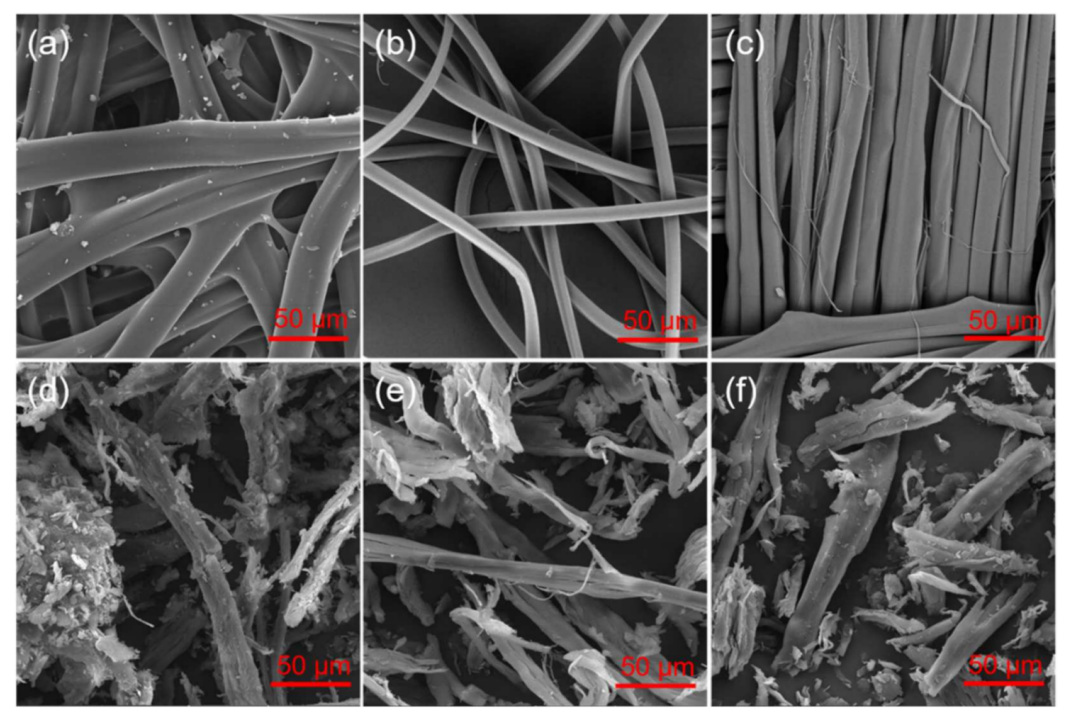

Figure 3. SEM images of (a) raw silk cocoons, (b) degummed silk cocoons, (c) silk fabric, and silk powders from (d) raw cocoons, (e) degummed cocoons, and (f) silk fabric.

EDS analysis revealed the main elements corresponding to silk chemical composition, such as carbon $(\mathrm{C})$, nitrogen $(\mathrm{N})$, and oxygen $(\mathrm{O})$ for all samples. Moreover, raw cocoons contained trace amounts of calcium (Ca), sulfur (S), and potassium (K) (Table 1). Ca is one of the fingerprints of natural silk [14]. However other elements such as $\mathrm{S}, \mathrm{K}$, and also sodium $(\mathrm{Na})$ and chloride $(\mathrm{Cl})$ were previously noted in a trace amount in the composition of $B$. mori cocoons before the degumming process [15]. The cocoons after removing sericin and for silk fabric did not reveal the presence of the above-mentioned elements since they were clear away by rinsing in water after the degumming process. The degummed cocoons were only composed of $\mathrm{C}, \mathrm{N}$, and $\mathrm{O}$. The trace amount of sodium (Na) was noted for cocoons without sericin and for silk fabric (Table 1) due to applying sodium carbonate as a degumming agent. EDS study confirmed the chemical composition of the source materials in comparison to other reports and indicated that the cryogenic milling process did not affect their composition significantly. 
Table 1. Results of EDS analysis of raw silk cocoons, degummed cocoons, silk fabric, and their powders.

\begin{tabular}{|c|c|c|c|c|c|c|c|}
\hline & $\begin{array}{c}\mathrm{C} \\
\text { (wt.\%) }\end{array}$ & $\begin{array}{c}\mathrm{N} \\
\text { (wt.\%) }\end{array}$ & $\begin{array}{c}\mathrm{O} \\
\text { (wt. \%) }\end{array}$ & $\begin{array}{c}\mathrm{Ca} \\
\text { (wt.\%) }\end{array}$ & $\begin{array}{c}\text { S } \\
\text { (wt.\%) }\end{array}$ & $\begin{array}{c}\mathrm{K} \\
\text { (wt.\%) }\end{array}$ & $\begin{array}{c}\mathrm{Na} \\
\text { (wt.\%) }\end{array}$ \\
\hline raw cocoons & $44.5 \pm 0.3$ & $16.9 \pm 0.3$ & $37.6 \pm 0.5$ & $0.6 \pm 0.1$ & $\sim 0.2$ & $\sim 0.2$ & \\
\hline $\begin{array}{l}\text { raw cocoons- } \\
\text { powder }\end{array}$ & $46.3 \pm 0.6$ & $17.5 \pm 0.5$ & $35.4 \pm 0.5$ & $\sim 0.3$ & $\sim 0.1$ & $\sim 0.3$ & \\
\hline $\begin{array}{l}\text { degummed } \\
\text { cocoons }\end{array}$ & $52.4 \pm 0.6$ & $19.7 \pm 0.3$ & $27.6 \pm 0.5$ & & & & $\sim 0.2$ \\
\hline $\begin{array}{l}\text { degummed } \\
\text { cocoons- } \\
\text { powder }\end{array}$ & $48.8 \pm 0.1$ & $20.6 \pm 0.2$ & $30.5 \pm 0.1$ & & & & $\sim 0.1$ \\
\hline $\begin{array}{l}\text { silk woven } \\
\text { fabric }\end{array}$ & $48.8 \pm 0.4$ & $20.9 \pm 0.4$ & $30.2 \pm 0.3$ & & & & $\sim 0.3$ \\
\hline $\begin{array}{c}\text { silk woven } \\
\text { fabric- } \\
\text { powder }\end{array}$ & $51.9 \pm 0.7$ & $19.0 \pm 0.4$ & $28.9 \pm 0.3$ & & & & $\sim 0.3$ \\
\hline
\end{tabular}

\subsection{Raman Studies}

To study the protein conformation and the influence of cryogenic milling on silk materials Raman spectroscopy analysis were implemented to the report. Figure 4 and Figure S2 show Raman spectra of all samples before and after the milling process. It is clearly visible that all spectra revealed the same bands responsible for specific assignments of silk native structure, indicating no significant influence of degumming and cryogenic milling on the fibroin structure. The peak at $1660 \mathrm{~cm}^{-1}$ related to the amide I of $\beta$-sheets $\mathrm{C}=\mathrm{O}$ stretching [16] is present in all spectra at comparable intensity and the same value of Raman shift. $\beta$-sheets structure of amine III is also visible for all samples as the bands at 1221 and $1256 \mathrm{~cm}^{-1}$ [17]. The intensity of the band at $1221 \mathrm{~cm}^{-1}$ decreased for the powders, especially for raw and degummed cocoons, in comparison to $1256 \mathrm{~cm}^{-1}$ band related to disordered form of $\beta$-sheets amide III. It indicates that milling process resulted in the increase the number of regions of the protein chain, which do not form regular secondary structure of amide III. However, the presence of the bands corresponding to $\beta$-sheets of amide I and amine III indicate the crystalized regions of fibroin regardless to milling process. The bands at 3062,2935 , and $2876 \mathrm{~cm}^{-1}$ related, respectively, to C-N-H bending, $\mathrm{CH}_{3}$ asymmetric stretching, and $\mathrm{CH}_{3}$ asymmetric stretching visible in all Raman spectra demonstrate that fibroin structure were well preserved [17].

The changes in the intensity of other selected bands were noted. The band at $1393 \mathrm{~cm}^{-1}$ originating from $\beta$-sheet parts of poly-L-alanine [18] decreased after the milling process in comparison to the band at $1443 \mathrm{~cm}^{-1}$ corresponding to $\mathrm{CH}_{2}, \mathrm{CH}_{3}$ bending in alanine [19]. It indicates that cryogenic milling process effectively cut the long aminoacidic sequences, such as polyalanine to smaller parts. The spectra of raw cocoon and degummed samples are very similar due to the fact that Raman spectroscopy does not clearly distinguish sericin presence. It was found previously that the Raman intensity of the sericin was found to be negligible [20]. 


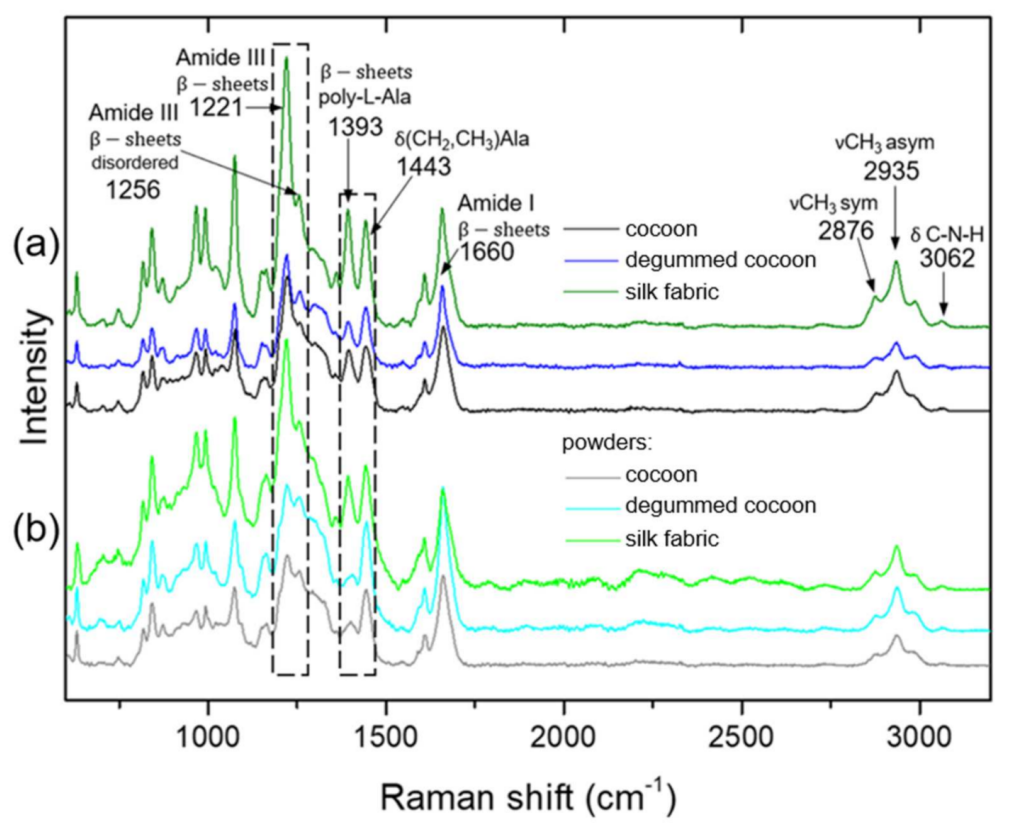

Figure 4. Raman spectra of (a) raw silk cocoons, degummed cocoons, and silk fabric; and (b) silk powders from raw cocoons, degummed cocoons, and silk fabric.

\subsection{Fourier Transformed Infrared (FTIR) Analysis}

The infrared spectroscopy studies were applied as complementary data to Raman spectroscopy results. FTIR analysis is a valuable tool for the evaluation of silk fibroin secondary structure and individual components of silk samples, including sericin. The characteristic infrared bands indicate different conformations of silk protein structure. FTIR spectra were measured for raw and degummed silk cocoons as well as silk fabric. Moreover, the spectra were collected and analyzed for all of the above-mentioned samples after the cryogenic milling process (Figure 5 and Figure S3). The main peaks characteristic of silk fibroin were noted for raw cocoons, degummed cocoons, and fabric at the maximum of 1618,1514 , and $1262 \mathrm{~cm}^{-1}$ indicating $\beta$-sheets crystallites of, respectively, amide I, II, and III (Figure 5a) [21]. The amides bands connected with $\beta$-sheets conformation did not change after the degumming process indicating preserving the silk structure. The band at a maximum of $1233 \mathrm{~cm}^{-1}$ corresponding to a random coil of amide III [22] also did not change for all samples indicating that this structure of fibroin parts remained unchanged. In Figure $5 \mathrm{a}$, the band at about $3274 \mathrm{~cm}^{-1}$ revealed a broad peak for raw cocoons indicating the contribution of sericin characterized with a more random structure than high crystalline fibroin with stacked $\beta$-sheets. After the degumming process and for silk fabric, the band is narrower, demonstrating an efficient sericin removing process [23]. The evaluation of the degumming process is also possible by examination of the presence of different peaks, for example at $1400 \mathrm{~cm}^{-1}$ connected with sericin and present only in raw silk cocoon sample (Figure 6a and Figure S4) [23]. Moreover, the sample without sericin or with its little amount shows two bands at 975 and $1000 \mathrm{~cm}^{-1}$ indicating, respectively, an abundance of -glycine-alanine- and -glycine-glycine- fragments in polypeptide chain (Figure 6 and Figure S4) [23]. The evidence of sericin presence before the degumming process is visible in the infrared peak at $1070 \mathrm{~cm}^{-1}$, whose intensity is relatively higher for the sample not chemically treated and decreases with increasing the content of the fibroin in the silk-based materials [23]. The low-intensity peak at $2921 \mathrm{~cm}^{-1}$ responsible for stretching vibration of $\mathrm{CH}_{2}$ is only observed in raw silk (Figure 5a and Figure S3) due to the sericin presence [24]. It was also noted that after the degumming process a band with the maximum at $1262 \mathrm{~cm}^{-1}$ of amine III band in comparison of $1233 \mathrm{~cm}^{-1}$ band became more evident after removing sericin due to the increasing content of $\beta$-sheet crystallites of fibroin in the sample (Figure 6a and Figure S4). The intensity of the band increases with increasing 
degumming time and ratio [25]. After the milling process, the peak at $1262 \mathrm{~cm}^{-1}$ is not so apparent due to an increase in the intensity of $1233 \mathrm{~cm}^{-1}$ band related to non-oriented $\beta$-sheet arrangement in silk fibroin of amide III.

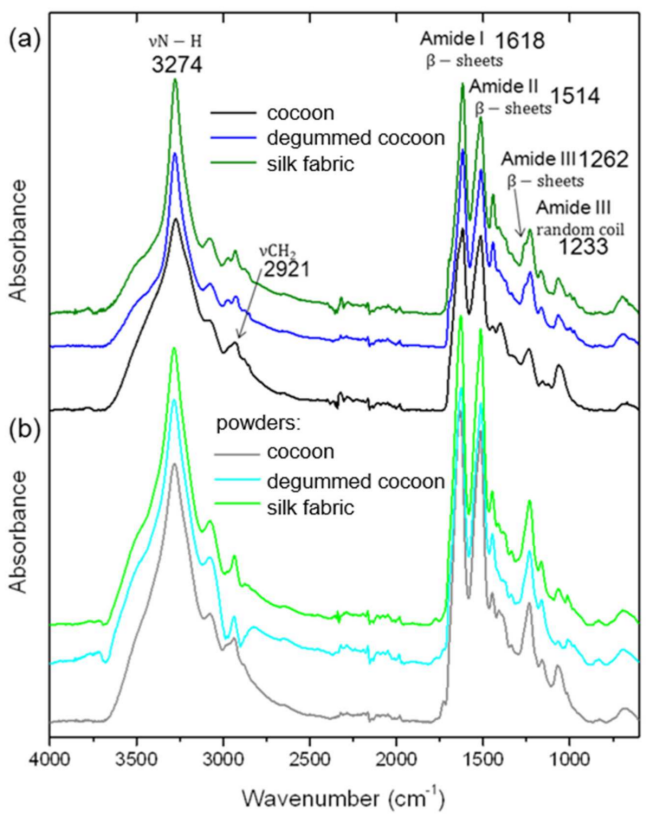

Figure 5. Infrared absorption spectra of (a) raw, and degummed silk cocoons, silk fabric, and (b) silk powders from raw cocoons, degummed cocoons, and silk fabric.

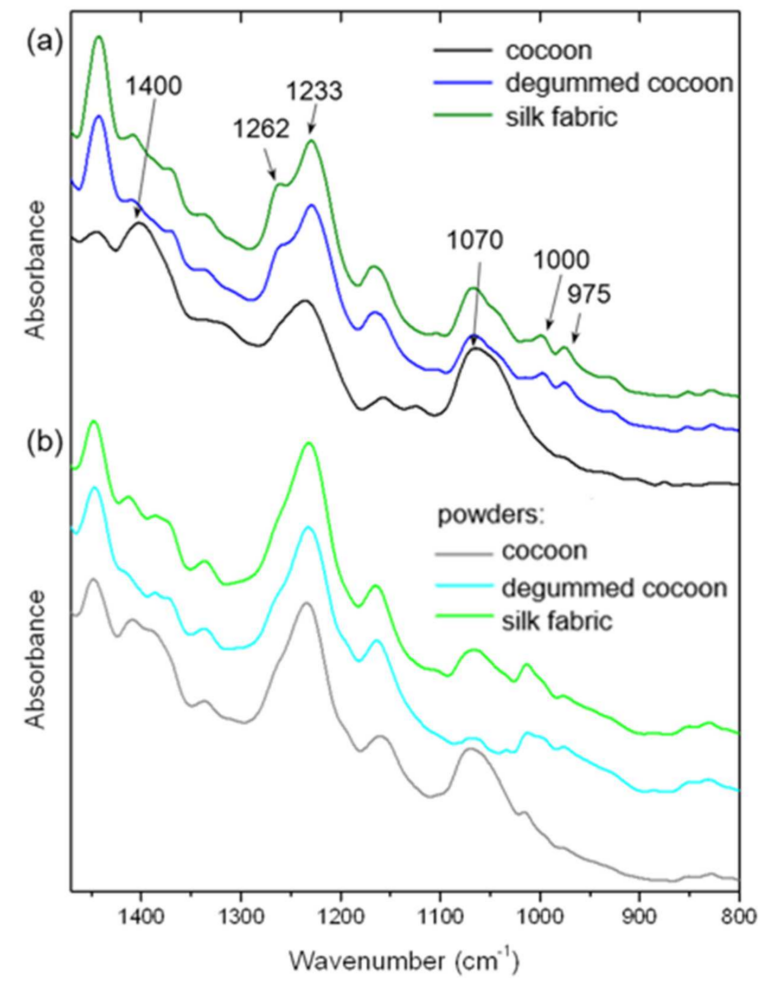

Figure 6. Infrared absorption spectra of (a) raw, and degummed silk cocoons, silk fabric and (b) silk powders from raw cocoons, degummed cocoons, and silk fabric.

The maxima of the main peaks from the infrared fingerprint region for amide II and amide III did not shift for all powders regardless of the silk source. The maxima of the amide I band slightly shifted to the higher values of 1632,1626 , and $1629 \mathrm{~cm}^{-1}$, 
respectively, for raw, degummed cocoons, and fabric indicating rearrangement in $\beta$-sheet conformation involving $\mathrm{C}=\mathrm{O}$ stretching in tyrosine. The presence of the three main amides bands after the milling process demonstrates that $\beta$-sheets crystallites parts of fibroin were preserved for all powders. Moreover, bands for a random coil of amide III at $1233 \mathrm{~cm}^{-1}$ were also noticeable after milling indicating that amorphous parts of the fibroin also did not significantly change. The main infrared peaks of the powders indicate that the main secondary conformation of $\beta$-sheets and random coil for silk was retained after degumming and milling processes. Additionally, infrared spectra do not show any others picks besides characteristic silk bands that confirmed the native secondary conformation of silk protein fibers was preserved.

\subsection{Thermal Analysis}

The DSC analysis of the silk samples was also carried out to define their thermal properties and compered source silk materials to their powdered form (Figure 7). Figure 7 shows thermograms of raw silk cocoons, degummed cocoons, and silk fabric, before and after the milling process. The detailed results are given in Table S1. A broad endothermic peak (denoted as Tw) cantered around $60^{\circ} \mathrm{C}$ correspond to water loss was noted for all samples. The samples were stored at the same conditions characterized by humidity of $50 \%$ and temperature of $23 \pm 2{ }^{\circ} \mathrm{C}$. The maximum of the peak for silk-based materials before milling slightly varies and appears at the highest temperature of $62{ }^{\circ} \mathrm{C}$ for raw cocoons since removing water molecules from silk fiber entwined is more difficult than from fabric. Tw peak maximum for degummed cocoons is noted at about $52{ }^{\circ} \mathrm{C}$ due to the fact that they are previously dried after sericin rinsing in an aqueous solution. Based on the dry mass of raw cocoons before and after degumming it was calculated that fibroin content is about $73 \mathrm{wt} . \%$, which is consistent with other reports [3]. The endothermic Tw peak for powders is centered about $60^{\circ} \mathrm{C}$ for all milled samples, indicating water absorption by the powders and its evaporation during the measurements.

DSC analysis of raw cocoons indicated their thermal decomposition in the temperature range of 270.9 to $337.3{ }^{\circ} \mathrm{C}$ and endothermic peak at about $317.2{ }^{\circ} \mathrm{C}$, denoted as $\mathrm{T}_{\mathrm{d}}$ and corresponded to degradation of $\beta$-sheet structures [26,27]. This temperature range changed slightly after the raw cocoon milling process and was noted from $268.9^{\circ} \mathrm{C}$ to $335.3^{\circ} \mathrm{C}$. The endothermic peak was shifted by $4.5^{\circ} \mathrm{C}$ to a lower value and was estimated to be about $312.7^{\circ} \mathrm{C}$ indicating lower thermal stability of the cocoons after the milling process due to breakage of amide bonds and non-oriented $\beta$-sheet arrangement in the silk fibroin structure [28]. This phenomenon was also noted for the cocoons without sericin; the onset and end temperatures for degummed samples were noted, respectively, at $272.8^{\circ} \mathrm{C}$ and $342.9^{\circ} \mathrm{C}$ before and $263.4{ }^{\circ} \mathrm{C}$ and $334.8^{\circ} \mathrm{C}$ after the milling process. The endothermic peak was shifted by $10.7^{\circ} \mathrm{C}$ from a value of $320.3^{\circ} \mathrm{C}$ to $309.6^{\circ} \mathrm{C}$ due to decreasing thermal degradation temperature. The silk fabric thermal properties revealed the lowest thermal stability before as well as after the grinding process. Even though the decomposition range of the fabric is similar to raw cocoon values of $274.0^{\circ} \mathrm{C}$ to $336.1^{\circ} \mathrm{C}$, the maximum of the endothermic peak was noted at $314.9^{\circ} \mathrm{C}$. After the milling process of silk fabric, the thermal decomposition process was carried out at significantly lower temperature values. The onset and end temperatures were measured to be $258.6^{\circ} \mathrm{C}$ and $334.0^{\circ} \mathrm{C}$, respectively. The maximum of the endothermic peak shifted about $12{ }^{\circ} \mathrm{C}$ to the value of $301.8^{\circ} \mathrm{C}$ demonstrating the significant impact of the grinding process on the thermal properties of silk fabric and making them lower thermally resistant. The degradation enthalpy value $\left(\Delta \mathrm{H}_{\mathrm{deg}}\right)$ for raw cocoons, after removing sericin and for silk fabric was determined to be $228.5,278.9$, and $331.9 \mathrm{~J} / \mathrm{g}$, respectively. $\Delta \mathrm{H}_{\mathrm{deg}}$ values after the milling process were estimated to be $257.7,286.1$, and $333.7 \mathrm{~J} / \mathrm{g}$, respectively, for the powders from raw cocoons, degummed cocoons, and fabric. The heat of the thermal decomposition of the silk samples after grinding increased slightly, indicating that the thermal stability of the samples has not changed significantly, while the onset, end, and endothermic peak maximum were shifted to the lower values. To evaluate the significance level of the thermal decomposition 
temperatures of the samples before and after the milling process the statistical $t$-test was performed. It was found that significant differences $(p<0.05)$ were noted for endothermic peak position for milled raw cocoons, end temperature of the process for degummed cocoons, and the maximum of the peak and end temperature for silk fabric.

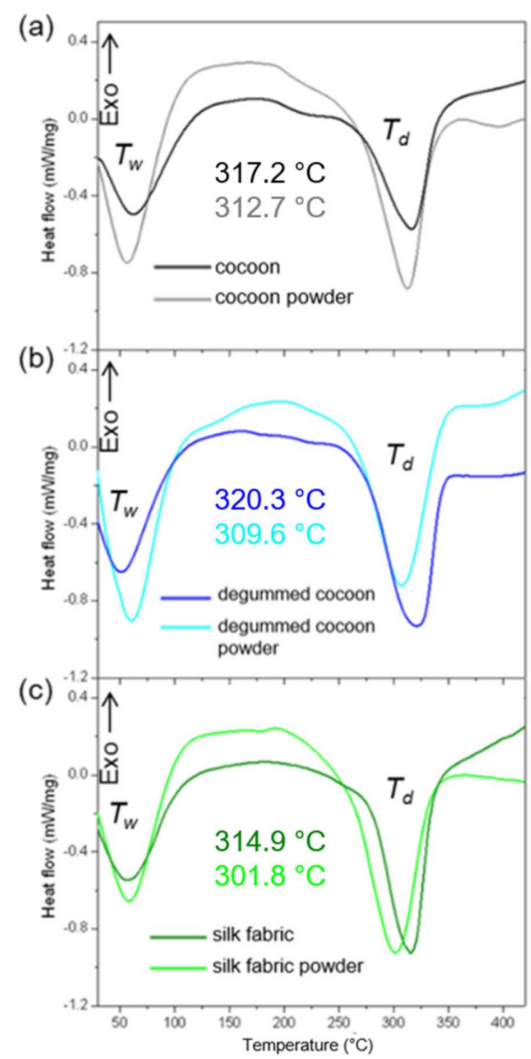

Figure 7. DSC thermograms of (a) raw and (b) degummed silk cocoons, and (c) silk fabric, and silk powders from (a) raw cocoons, (b) degummed cocoons, and (c) silk fabric.

The thermogravimetric analysis (Figure 8) revealed an initial weight loss in all samples at about $60{ }^{\circ} \mathrm{C}$ related to water evaporation, which is consistent with the DSC results. The main process in the studied range of temperatures is connected to heat absorption for the decomposition of silk-based materials. In the region from $250{ }^{\circ} \mathrm{C}$ to $350{ }^{\circ} \mathrm{C}$ (Figure $8 \mathrm{~b}$ ), the rapid increase in weight loss is observed due to the breakage of peptide bonds and reduction of intermolecular interactions [29]. The thermal decomposition of raw and degummed cocoons and their powders started at about $281.0^{\circ} \mathrm{C}$. The process onset temperature for silk fabric and its powdered form was lower by about $2{ }^{\circ} \mathrm{C}$ indicating lower resistance to heat for silk fabric and its powder. The detailed results are given in Table S2. It was found that the milling process not affected significantly the starting temperature of the thermal decomposition process. The maximum of the thermal decomposition peak was noted at $316.3,314.2$, and $309.6^{\circ} \mathrm{C}$ for raw and degummed cocoons and woven fabric, respectively. The values were characteristic for silk-based materials [30] and indicated the highest thermal resistivity for raw cocoons and the lowest one for silk fabric. The earlier degradation temperature for the fabric may be attributed to a decrease of molecular weight of peptide chains due to previous manufacturing processes of silk fabric [29]. The thermal degradation peak after the milling process was found to be about 308.5, 308.2, and $300.2{ }^{\circ} \mathrm{C}$, respectively, for raw cocoons, degummed cocoons, and fabric. The peak was shifted slightly by about $8{ }^{\circ} \mathrm{C}\left(7.8 \pm 0.5^{\circ} \mathrm{C}\right), 6^{\circ} \mathrm{C}\left(6.0 \pm 1.1^{\circ} \mathrm{C}\right)$, and $9{ }^{\circ} \mathrm{C}\left(9.4 \pm 1.2^{\circ} \mathrm{C}\right)$ to lower temperatures demonstrate that the milling process makes silk less thermally resistant material. To analyze the relevance of the milling on the decomposition process the significance level was estimated ( $t$-test) for the thermal decomposition temperatures of the samples before 
and after the grinding process. The significant changes $(p<0.05)$ were indicated for end temperature of decomposition process raw cocoon and its powder; onset, end temperatures, and a maximum of the peak for degummed cocoon in comparisons to its powder; and end temperature and peak position for silk fabric and its powder. The thermal processes were significantly influenced by the milling process. However, the maximum of the thermal degradation peak was noted still above $300{ }^{\circ} \mathrm{C}$ indicating that the high thermal stability of the silk was retained for all powders.

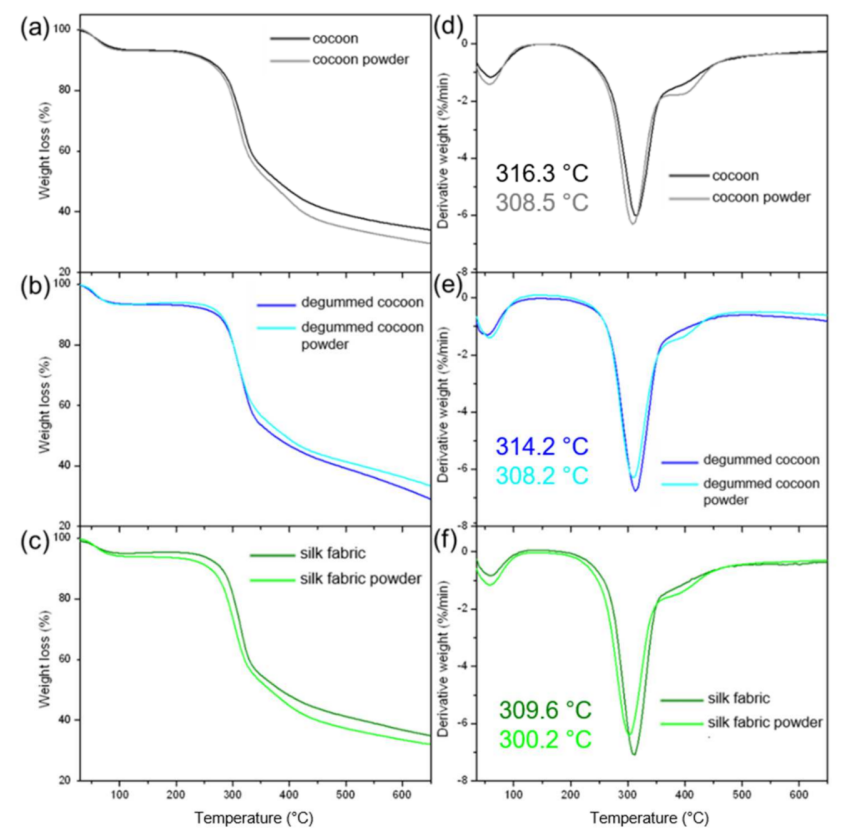

Figure 8. (a-c) TG and (d-f) DTG thermograms of $(\mathbf{a}, \mathbf{d})$ raw and $(\mathbf{b}, \mathbf{e})$ degummed silk cocoons, and (c,f) silk fabric, and silk powders from (a,d) raw cocoons, $(\mathbf{b}, \mathbf{e})$ degummed cocoons, and $(\mathbf{c}, \mathbf{f})$ silk fabric.

\section{Conclusions}

The study demonstrates an easy method of obtaining silk powder from raw cocoons, degummed cocoons, and silk woven fabric. The powder from raw cocoons is composed of fibroin and sericin, while degummed cocoons and silk fabric are ground into fibroin powder. The silk-based materials are pulverized using cryogenic milling. The low-temperature process is applied to minimize the changes in secondary silk conformation. FTIR and Raman spectroscopies revealed that the powders retained dominant $\beta$-sheet structure and some random coil fragments. The rearrangement was only noted in the $\beta$-sheet amide III part and fragmentation of poly-L-Ala fragments due to the milling process. The thermal properties of the powders also show characteristic decomposition for silk materials. The thermal endothermic peak and onset temperature shifted to the lower values for all powders indicating their less thermal stability, especially silk woven fabric and its powder. However, the process of sericin/fibroin and fibroin powder formation is found to be efficient and beneficial due to mild temperature conditions and no use harsh solvents. The powders can extend silk applications as a bio-modifier of various systems due to easy introduction into different matrices or forming coating to enrich them with new properties and make them biocompatible.

Supplementary Materials: The following are available online at https: / www.mdpi.com/article/ 10.3390/ma14226919/s1. Figure S1: SEM images of (a) the top view, (b) cross-sectional view, and along the fibers of silk woven fabric; Figure S2: Raman spectra of (a) raw silk cocoons, (b) degummed cocoons, and (c) silk fabric, and silk powders from (a) raw cocoons, (b) degummed cocoons, and (c) silk fabric; Figure S3: Infrared absorption spectra of (a) raw, and (b) degummed silk cocoons, (c) silk fabric, and silk powders from (a) raw cocoons, (b) degummed cocoons, and (c) silk fabric; 
Figure S4: Infrared absorption spectra of (a) raw, and (b) degummed silk cocoons, (c) silk fabric, and silk powders from (a) raw cocoons, (b) degummed cocoons, and (c) silk fabric; Table S1: The onset, and end temperatures, peak $\left(\mathrm{T}_{\mathrm{d}}\right)$ of degradation process, and degradation enthalpy value $\left(\Delta \mathrm{H}_{\mathrm{deg}}\right)$ obtained from DSC analysis for raw, degummed silk cocoons and silk woven textile before and after cryogenic milling; Table S2: The onset, and end temperatures, and peak of degradation process, obtained from TG/DTG analysis for raw, degummed silk cocoons and silk woven textile before and after cryogenic milling.

Author Contributions: Conceptualization, A.B.-K. and M.C.; methodology, A.B.-K.; validation, A.B.-K. and M.C.; formal analysis, A.B.-K.; investigation, A.B.-K., A.H., I.K.; resources, M.C.; writingoriginal draft preparation, A.B.-K.; writing-review and editing, A.B.-K. and M.C. All authors have read and agreed to the published version of the manuscript.

Funding: The study was carried out in the frame of statutory activities (BZT 01 70) of the Textile Research Institute in 2021 financed by the Ministry of Science and Higher Education.

Institutional Review Board Statement: Not applicable.

Informed Consent Statement: Not applicable.

Data Availability Statement: The data presented in this study are available on request from the corresponding author.

Acknowledgments: The Raman spectroscopy measurements were carried out on Raman Renishaw InVia Spectrometer purchased the in POIG.01.03.01-00-004/08 Functional nano- and micro textile materials-NANOMITEX project, co-financed by the European Union with the financial resources of the European Regional Development Fund and the National Centre for Research and Development.

Conflicts of Interest: The authors declare no conflict of interest.

\section{References}

1. Badawy, I.M.; Ali, B.A.; Abbas, W.A.; Allam, N.K. Natural silk for energy and sensing applications: A review. Environ. Chem. Lett. 2021, 19, 2141-2155. [CrossRef]

2. Koh, L.D.; Cheng, Y.; Teng, C.P.; Khin, Y.W.; Loh, X.J.; Tee, S.Y.; Low, M.; Ye, E.; Yu, H.D.; Zhang, Y.W.; et al. Structures, mechanical properties and applications of silk fibroin materials. Prog. Polym. Sci. 2015, 46, 86-110. [CrossRef]

3. Wang, C.; Xia, K.; Zhang, Y.; Kaplan, D.L. Silk-Based Advanced Materials for Soft Electronics. Acc. Chem. Res. 2019, 52, 2916-2927. [CrossRef] [PubMed]

4. Holland, C.; Numata, K.; Rnjak-Kovacina, J.; Seib, F.P. The Biomedical Use of Silk: Past, Present, Future. Adv. Healthcare Mater. 2019, 8, 1800465. [CrossRef]

5. Kumar, J.P.; Alam, S.; Jain, A.K.; Ansari, K.M.; Mandal, B.B. Protective Activity of Silk Sericin against UV Radiation-Induced Skin Damage by Downregulating Oxidative Stress. ACS Appl. Bio Mater. 2018, 1, 2120-2132. [CrossRef]

6. Zhang, X.; Tsukada, M.; Morikawa, H.; Aojima, K.; Zhang, G.; Miura, M. Production of silk sericin/silk fibroin blend nanofibers. Nanoscale Res. Lett. 2011, 6, 510. [CrossRef] [PubMed]

7. Rajkhowa, R.; Wang, L.; Wang, X. Ultra-fine silk powder preparation through rotary and ball milling. Powder Technol. 2008, 185, 87-95. [CrossRef]

8. Rajkhowa, R.; Wang, L.; Kanwar, J.; Wang, X. Fabrication of ultrafine powder from eri silk through attritor and jet milling. Powder Technol. 2009, 191, 155-163. [CrossRef]

9. Xiao, S.; Wang, Z.; Ma, H.; Yang, H.; Xu, W. Effective removal of dyes from aqueous solution using ultrafine silk fibroin powder. Adv. Powder Technol. 2014, 25, 574-581. [CrossRef]

10. Zhao, M.; Qi, Z.; Tao, X.; Newkirk, C.; Hu, X.; Lu, S. Chemical, thermal, time, and enzymatic stability of silk materials with silk i structure. Int. J. Mol. Sci. 2021, 22, 4136. [CrossRef] [PubMed]

11. Schmidt, R.; Martin Scholze, H.; Stolle, A. Temperature progression in a mixer ball mill. Int. J. Ind. Chem. 2016, 7, 181-186. [CrossRef]

12. Holland, C.; Hawkins, N.; Frydrych, M.; Laity, P.; Porter, D.; Vollrath, F. Differential Scanning Calorimetry of Native Silk Feedstock. Macromol. Biosci. 2019, 19, 6-11. [CrossRef] [PubMed]

13. Rocha, L.K.H.; Favaro, L.I.L.; Rios, A.C.; Silva, E.C.; Silva, W.F.; Stigliani, T.P.; Guilger, M.; Lima, R.; Oliveira, J.M.; Aranha, N.; et al. Sericin from Bombyx mori cocoons. Part I: Extraction and physicochemical-biological characterization for biopharmaceutical applications. Process Biochem. 2017, 61, 163-177. [CrossRef]

14. Boonyawan, D. Atmospheric Pressure Plasma Jet Induced Graft-Polymerization for Flame Retardant Silk. In Advanced Plasma Spray Applications; InTech: Rijeka, Croatia, 2012. [CrossRef]

15. Tulachan, B.; Meena, S.K.; Rai, R.K.; Mallick, C.; Kusurkar, T.S.; Teotia, A.K.; Sethy, N.K.; Bhargava, K.; Bhattacharya, S.; Kumar, A.; et al. Electricity from the silk cocoon membrane. Sci. Rep. 2014, 4, 38-42. [CrossRef] [PubMed] 
16. Puchowicz, D.; Cieslak, M. Raman Spectroscopy in the Analysis of Textile Structures. In Recent Developments in Atomic Force Microscopy and Raman Spectroscopy for Materials Characterization; IntechOpen: Rijeka, Croatia, 2021; pp. 1-21. [CrossRef]

17. Narita, C.; Okahisa, Y.; Wataoka, I.; Yamada, K. Characterization of ground silk fibroin through comparison of nanofibroin and higher order structures. ACS Omega 2020, 5, 22786-22792. [CrossRef]

18. Lefèvre, T.; Paquet-Mercier, F.; Rioux-Dubé, J.F.; Pézolet, M. Review: Structure of silk by Raman spectromicroscopy: From the spinning glands to the fibers. Biopolymers 2012, 97, 322-336. [CrossRef]

19. Zhu, G.; Zhu, X.; Fan, Q.; Wan, X. Raman spectra of amino acids and their aqueous solutions. Spectrochim. Acta-Part A Mol. Biomol. Spectrosc. 2011, 78, 1187-1195. [CrossRef] [PubMed]

20. Yuan, Y.; Liu, H.; Zheng, N.; Gao, L.; Liu, F.; Guan, G.; Zhang, G. Simple fabrication of sericin/graphene nanocomposites for application in articular cartilage repair in knee joints in nursing care. Appl. Nanosci. 2020, 10, 695-702. [CrossRef]

21. Boulet-Audet, M.; Vollrath, F.; Holland, C. Identification and classification of silks using infrared spectroscopy. J. Exp. Biol. 2015, 218, 3138-3149. [CrossRef]

22. Koperska, M.A.; Pawcenis, D.; Bagniuk, J.; Zaitz, M.M.; Missori, M.; Łojewski, T.; Łojewska, J. Degradation markers of fibroin in silk through infrared spectroscopy. Polym. Degrad. Stab. 2014, 105, 185-196. [CrossRef]

23. Zhang, X.M.; Wyeth, P. Using FTIR spectroscopy to detect sericin on historic silk. Sci. China Chem. 2010, 53, 626-631. [CrossRef]

24. Bawazeer, T.M.; Alsoufi, M.S. Surface Characterization and Properties of Raw and Degummed (Bombyx mori) Silk Fibroin Fiber toward High Performance Applications of "Kisswa Al-Kabba". Int. J. Curr. Res. 2017, 9, 48335-48343.

25. Kim, H.J.; Chung, D.E.; Um, I.C. Effect of Processing Conditions on the Homogeneity of Partially Degummed Silk Evaluated by FTIR Spectroscopy. Int. J. Ind. Entomol. 2013, 26, 54-60. [CrossRef]

26. Mazzi, S.; Zulker, E.; Buchicchio, J.; Anderson, B.; Hu, X. Comparative thermal analysis of Eri, Mori, Muga, and Tussar silk cocoons and fibroin fibers. J. Therm. Anal. Calorim. 2014, 116, 1337-1343. [CrossRef]

27. Malay, A.D.; Sato, R.; Yazawa, K.; Watanabe, H.; Ifuku, N.; Masunaga, H.; Hikima, T.; Guan, J.; Mandal, B.B.; Damrongsakkul, S.; et al. Relationships between physical properties and sequence in silkworm silks. Sci. Rep. 2016, 6, 27573. [CrossRef] [PubMed]

28. Zhang, Y.Q.; De Shen, W.; Xiang, R.L.; Zhuge, L.J.; Gao, W.J.; Wang, W.B. Formation of silk fibroin nanoparticles in water-miscible organic solvent and their characterization. J. Nanopart. Res. 2007, 9, 885-900. [CrossRef]

29. Samie, M.; Muhammad, N.; Yameen, M.A.; Chaudhry, A.A.; Khalid, H.; Khan, A.F. Aqueous Solution of a Basic Ionic Liquid: A Perspective Solvent for Extraction and Regeneration of Silk Powder from Bombyx mori Silk Cocoons. J. Polym. Environ. 2020, 28, 657-667. [CrossRef]

30. Cheng, L.; Huang, H.; Zeng, J.; Liu, Z.; Tong, X.; Li, Z.; Zhao, H.; Dai, F. Effect of different additives in diets on secondary structure, thermal and mechanical properties of silkworm silk. Materials 2018, 12, 14. [CrossRef] 